\title{
Characterization and whole genome sequencing of a novel strain of Bergeyella cardium related to infective endocarditis
}

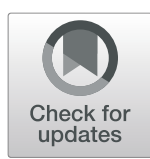

Hongwei Pan, Wei Li, Enhua Sun and Yi Zhang*

\begin{abstract}
Background: Bergeyella cardium infection is becoming increasingly prevalent in patients with infective endocarditis, suggesting its significance in disease pathogenesis. However, few studies have fully characterized this species.

Results: Herein, we report the morphological and physiological characteristics, as well as whole genome sequencing of a newly identified B. cardium HPQL strain isolated from a patient with infective endocarditis. Results from the cellular morphology and biochemical analysis provide basic knowledge on the new pathogen. The whole genome sequencing of $B$. cardium HPQL consists of a circular chromosome with a total length of 2,036,890 bp. No plasmid was detected. Comparative genomics were carried out then. Antibiotics resistance related genes, pathogenesis related genes, predicted insertion sequences, genome islands and predicted CRISPRs sequences were demonstrated. To our knowledge, this is the first study to provide a complete genome sequence for Bergeyella spp.

Conclusions: This study provides fundamental phenotypic and genomic information for the newly identified fastidious infective endocarditis causative bacteria, B. cardium. Our results provide insights into effective clinical diagnosis and treatment of this pathogen.
\end{abstract}

Keywords: Bergeyella cardium, Infective endocarditis, Genome sequencing

\section{Background}

Infective endocarditis is a serious infectious disease with high associated morbidity and mortality. Identification of the causative agents is, therefore, crucial for improving the clinical outcome [1]. Clinically, infective endocarditis is generally diagnosed based on positive blood cultures, removed leads, and/or infected pocket material [1]. Species belonging to the genera Streptococcus, Staphylococcus, and Enterococcus are the primary causative organisms of infective endocarditis [2]. However, recently new pathogens are emerging as additional etiological agents, such as Bergeyella spp. [3-5].

Bergeyella spp. are non-fermenting gram-negative bacilli, belonging to the family Flavobacteriaceae [3]. B. zoohelcum, known to cause cellulitis, leg abscess, tenosynovitis, septicemia, pneumonia, and meningitis, is one of the best described zoonotic pathogens afflicting

\footnotetext{
* Correspondence: yizhang@sdu.edu.cn

Department of Clinical Laboratory, Qilu Hospital of Shandong University, Jinan 250012, Shandong Province, China
}

humans $[6,7]$. B. zoohelcum is usually isolated from the normal oral microflora of animals such as cats and dogs [8]. Hence, animal bites and prolonged exposure to pets are the primary causes of human infection with $B$. zoohelcum [4]. In addition, a patient suffered B. zoohelcum bacteremia after eating food prepared with coagulated goat blood $[9,10]$. A case of cellulitis due to B. zoohelcum infection was also reported in a tsunami victim [9]. Alternatively, infections caused by other Bergeyella spp. are rarely reported. A previously uncultivated Bergeyella sp. (clone AF14) with strong homology to a previously reported uncultivated oral Bergeyella strain was suspected to be an opportunistic pathogen during preterm birth [11]. Further, the isolation of two Bergeyella strains was reported from patients with infective endocarditis. Both strains shared $94.9 \%$ homology with B. zoohelcum, suggesting that they are a new species belonging to of the genus Bergeyella. The two strains were designated as Bergeyella cardium $13-07^{\mathrm{T}}$ and Bergeyella cardium $13-16$ [3]. Meanwhile, another case study reported the isolation of a Bergeyella strain from an infective endocarditis

(c) The Author(s). 2020 Open Access This article is distributed under the terms of the Creative Commons Attribution 4.0 International License (http://creativecommons.org/licenses/by/4.0/), which permits unrestricted use, distribution, and 
patient that had $98.2 \%$ shared identity with B. zoohelcum, which was slightly lower than the $\geq 99.0 \%$ homology required for two organisms to be considered the same species [4]. Recently, a novel Bergeyella sp. was isolated from a patient with infective endocarditis. The organism was determined to be genetically most closely related to $B$. cardium [12]. Moreover, the first case of $B$. cardium prosthetic valve endocarditis was also reported quite recently [5].

The increasing number of cases of B. cardium infection in patients with infective endocarditis suggests its importance in disease pathogenesis. However, studies examining the microbial characteristics and genetic features of this species are very rare. In this study, we therefore, sought to describe the isolation, identification and characterization of a new B. cardium sp. from blood cultures of a patient with infective endocarditis. We also performed whole genome sequencing and, through phylogenetic analysis, we were able to predict the possible origin of this newly identified species.

\section{Results}

\section{Phylogenetic analysis identified the isolate as a novel} species of $B$. cardium

Four days after the initial blood culture was obtained from a 63-year-old man with infective endocarditis, the growth of microorganisms was reported through an automated blood culture system. Gram staining revealed the presence of gram-negative bacilli. However, no reliable identification was made by matrix-assisted laser desorption/ionization-time of flight mass spectrometry (MALDI-TOF MS). Thus, to accurately identify the pathogenic species, a $1425 \mathrm{bp}$ sequence from the $16 \mathrm{~S}$ rRNA gene of the isolated strain was amplified and sequenced via polymerase chain reaction (PCR). The sequence was then submitted to NCBI BLASTN to identify matched bacterial sequences. Results revealed that the sequence with the highest homology (approximately 99\%) was isolated from B. cardium. To further verify the nucleotide BLAST results, a detailed phylogenetic tree was constructed as shown in Fig. 1. Results showed the isolated strain clustering with two $B$. cardium strains that had been isolated from two infective endocarditis patients in Korea [3]. Hence, the phylogenetic analysis supported the finding that the isolated strain was a novel strain of $B$. cardium. We, therefore designated the isolated strain in our study as $B$. cardium HPQL (identified by Hongwei Pan from QiLu hospital).

\section{General microbial characteristics of B. cardium HPQL}

Morphological, physiological and biochemical characterization of the newly isolated strain was performed. We observed that the bacterial cells aggregate together in blood cultures (Fig. 2a). Moreover, small colonies of B. cardium HPQL were observed on blood agar after $48 \mathrm{~h}$ of incubation at $35^{\circ} \mathrm{C}$ (Fig. 2c). However, the

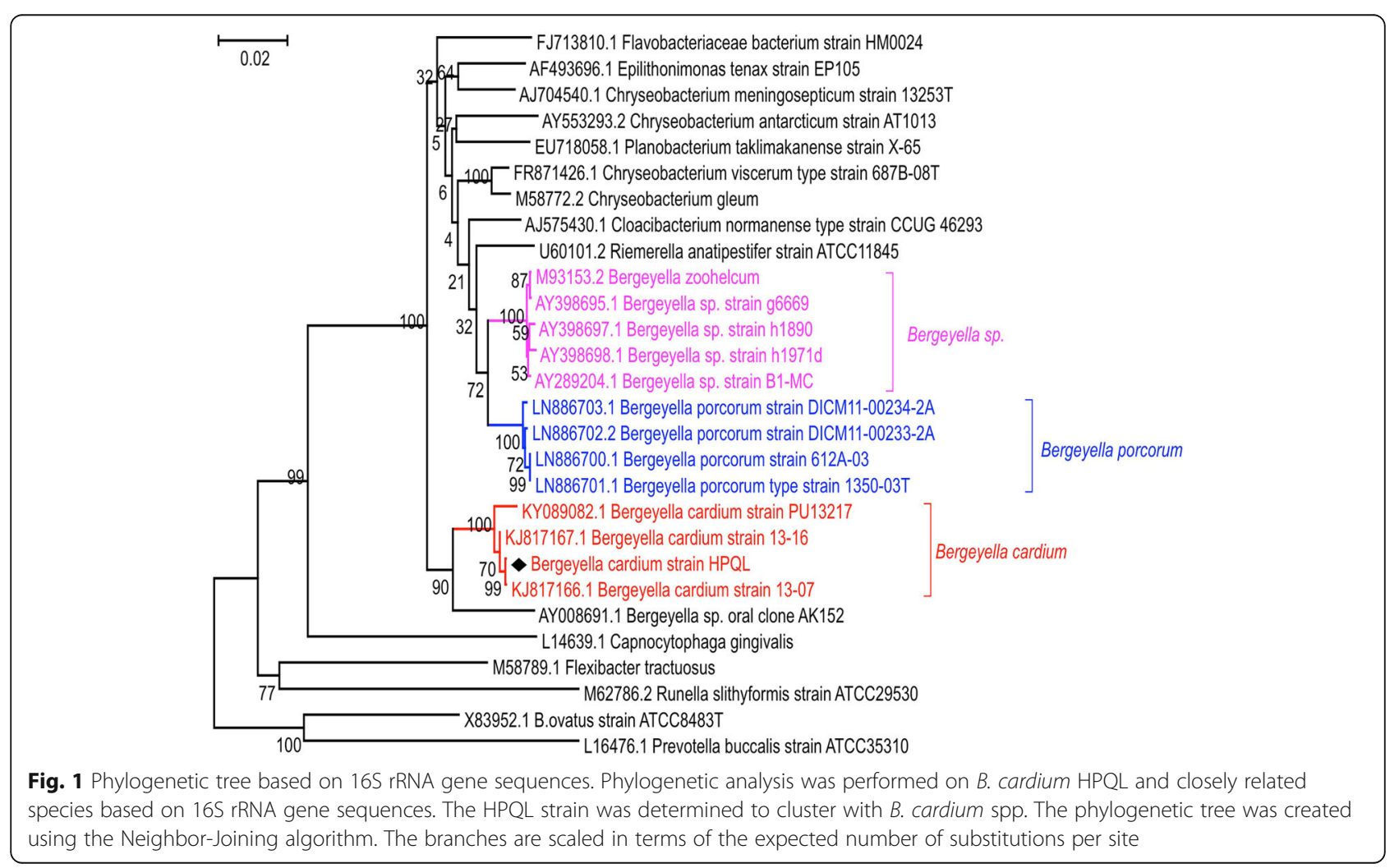




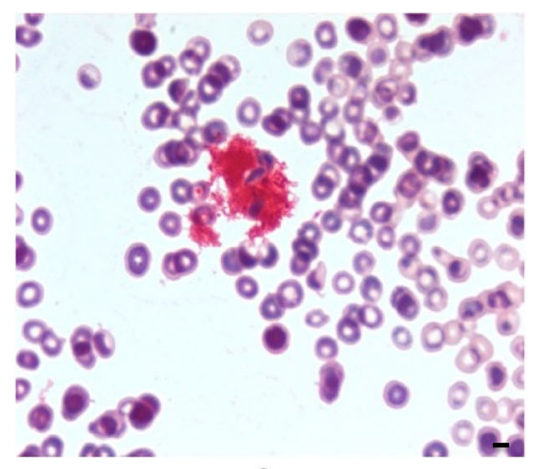

a

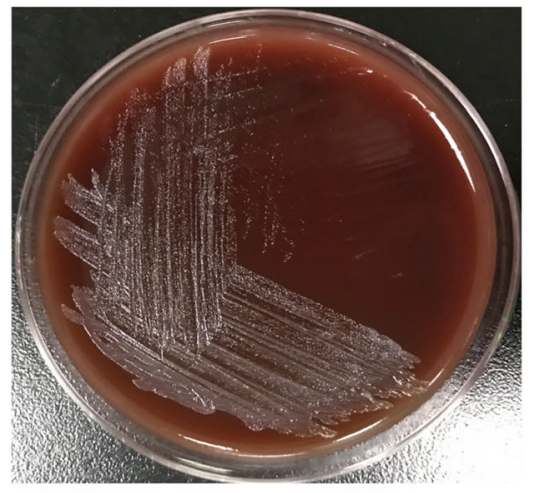

$\mathrm{C}$

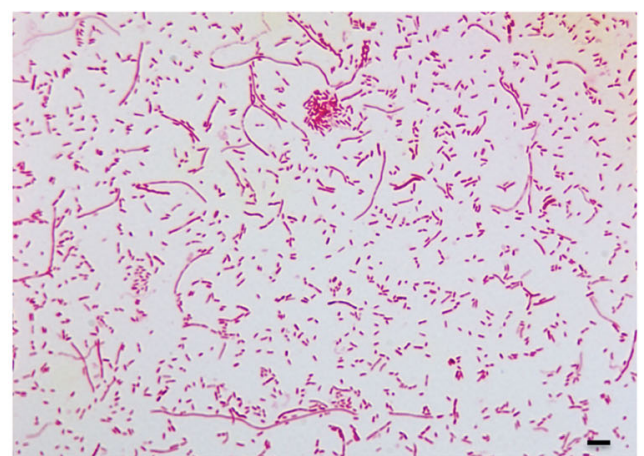

b

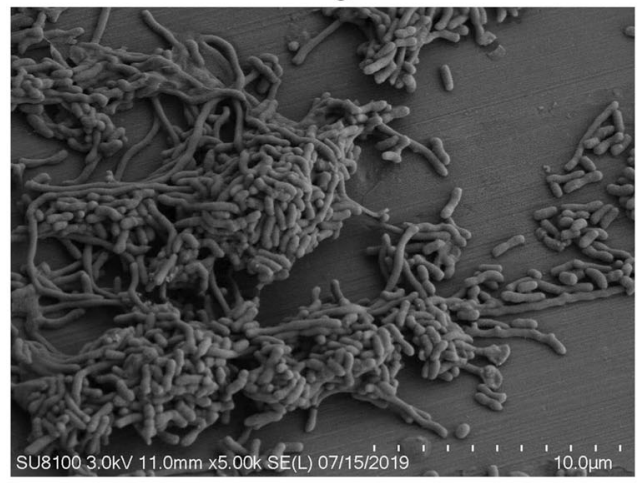

d

Fig. 2 Morphological characterization of B. cardium HPQL. a Bacterial cells cultured from positive blood cultures. The bar is equal to $5 \mu \mathrm{m}$. $\mathbf{b}$ Gram staining properties of the HPQL strain. The bar is equal to $20 \mu \mathrm{m}$. c Bacterial colonies after culturing for $48 \mathrm{~h}$ on Columbia blood agar. $\mathbf{d}$ Scanning electron microscope observation of the bacterial cells

strain did not grow on MacConkey agar or MuellerHinton agar plates, indicating that this organism exhibits fastidious growth patterns. Further, individual colonies grown on blood agar appeared as non-pigmented, circular, shiny, and smooth with entire edges (Fig. 2c). Microscopic and scanning electron microscope observation revealed irregularly rod-shaped bacterial cells (Fig. $2 b$ and d).

Biochemical characteristic of the strain were further analyzed. According to the results procured from API $\mathrm{NH}$, this bacterial strain did not produce penicillinase, omithine decarboxylase, urease, $\beta$-galactosidase, proline arylamidase or gamma glutamyl transferase. However, it was positive for lipase, alkaline phosphatase and oxidase activity, and negative for catalase activity and indole production. Additionally, acid was found to be produced from D-glucose, D-fructose, D-maltose, D-sucrose.

\section{Antimicrobial susceptibility analysis}

The E-test method was ultimately selected for AST analysis. MICs were determined following 4 days of growth on Columbia blood agar plates. The MICs for many of the selected antibiotics were quite low, with the exception of fluoroquinolones, chloramphenicol, azithromycin and gentamycin (Table 1).

\section{Genomic features of the $B$. cardium HPQL strain}

The whole genome of the newly isolated $B$. cardium HPQL strain was sequenced due to its potential clinical importance in patients with infective endocarditis. The genomic details are provided in Table 2 and Fig. 3a.

Table 1 Minimum inhibitory concentration of antimicrobial agents of $B$. cardium $\mathrm{HPQL}$

\begin{tabular}{ll}
\hline Antimicrobial agent $(\mu \mathrm{g} / \mathrm{mL})$ & MICs after $96 \mathrm{~h}$ incubation \\
\hline Penicillin & 0.032 \\
Ceftriaxone & 0.048 \\
Cefepime & 0.016 \\
Cefotaxime & 0.024 \\
Meropenem & 0.012 \\
Imipenem & 0.032 \\
Tigecycline & 0.032 \\
Amoxicillin/Clavulafiate & 0.016 \\
Sulfamethoxazole & 0.094 \\
Levofloxacin & 0.5 \\
Ciprofloxacin & 0.5 \\
Chloramphenicol & 3 \\
Azithromycin & 8 \\
Gentamycin & 64 \\
\hline
\end{tabular}


Table 2 Statistics of B. cardium HPQL genome

\begin{tabular}{lll}
\hline Attribute & Value & $\%$ of total \\
\hline Genome size (bp) & $2,036,890$ & $100 \%$ \\
\%GC content of genome & $39.63 \%$ & \\
Gene number & 1896 & $100 \%$ \\
Gene length & $1,813,065$ & $89.01 \%$ \\
Gene Average Length & 956 & \\
Genes with function prediction & 1332 & $70.25 \%$ \\
Genomic Island Numbers & 3 & $0.16 \%$ \\
Genomic Island total Length & 64,729 & $3.18 \%$ \\
No. of tRNA genes & 42 & $2.22 \%$ \\
No. of rRNA operons & 9 & $0.47 \%$ \\
No. of sRNA molecules & 1 & $0.05 \%$ \\
\hline
\end{tabular}

Briefly, B. cardium HPQL contained a circular chromosome with a total length of $2,036,890 \mathrm{bp}$. The GCcontent of the chromosome was determined to be $39.63 \%$. The whole genome sequence contained 1896 predicted coding sequences (CDS), including 9 rRNAs, 42 tRNAs and 1 sRNA. A total of 1,813,065 predicted coding sequences were identified, which occupied $89.01 \%$ of the whole genome sequence. Additionally, $70.25 \%(1332 / 1896)$ of the protein-coding genes were assigned putative functions in the COG database, while the remaining genes were annotated as encoding hypothetical proteins. The distribution of genes in COGs functional categories are presented in Table 3. In addition, the methylation data of the whole genome are listed in Additional file 3 (Sheet S1), Fig. 3b and deposited to REBASE database.

\section{Pathogenic analysis of $B$. cardium HPQL}

A whole genome BLAST search was performed against the CARD, VFDB, and PHI databases to identify genes related to antibiotic resistance and virulence factors in the genome of $B$. cardium HPQL. Twelve genes were identified homology to well-known antimicrobial resistance genes (Additional file 4 Sheet S2). Moreover, a total of 70 genes related to putative virulence factors were identified in the genome of $B$. cardium HPQL (Additional file 5 Sheet S3), while 92 genes were described that may participate in bacteria-host interactions (Additional file 6 Sheet S4).

\section{Comparative genomic analysis of $B$. cardium}

Three genome islands were predicted from the whole genome sequences (Additional file 7 Sheet S5). No prophage was predicted from the whole genome sequence of B. cardium HPQL, while 3 CRISPERs sequences (Additional file 1 Table S1), 30 insertion sequences

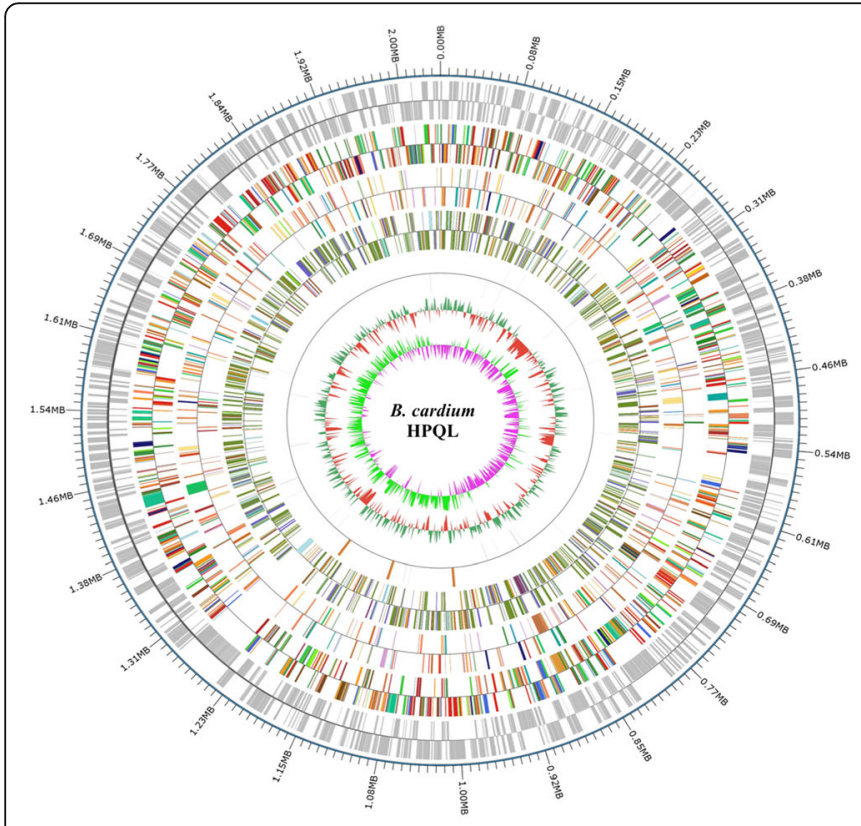

a

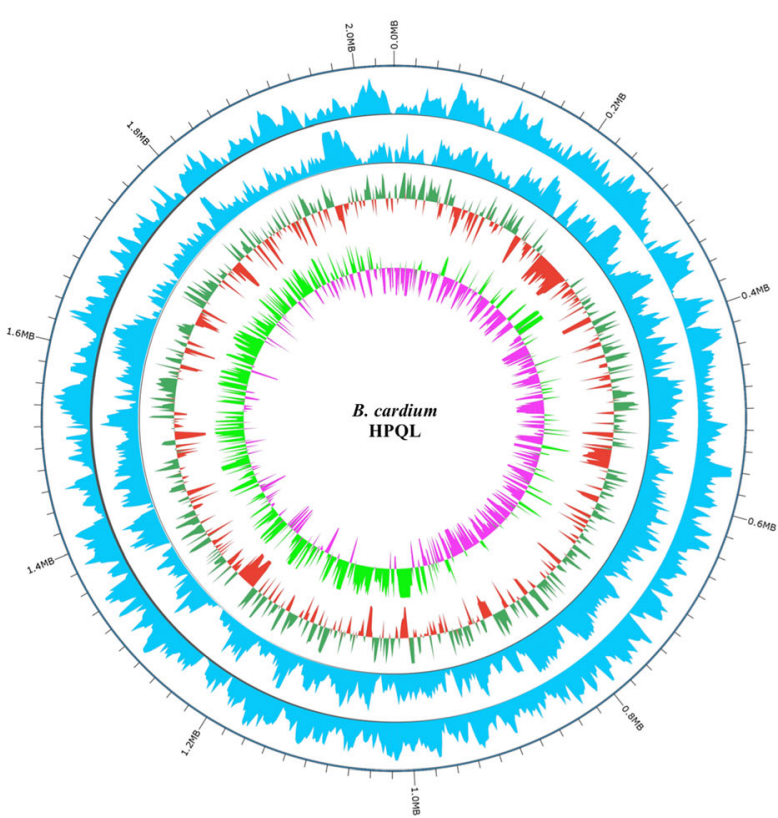

b

Fig. 3 Chematic map of the B. cardium HPQL genome and distribution map of epigenetic modification. a Chematic map of the B. cardium HPQL genome. From outside, Circle 1: genome positions in kb; Circle 2: predicted protein coding sequences (CDSs) on the forward (outer wheel) and the reverse (inner wheel) strands; Circle 3, Circle 4 and Circle 5: gene annotation results, colored according to COG, KEGG, GO classification, respectively; Circle 6: ncRNA; Circle 7: GC content and GC content deviations from the average. b Distribution map of epigenetic modification. From outside, Circle 1: genome positions in kb; Circle 2: modification in sense strand; Circle 3: modification in antisense strand; Circle 4: GC content and GC deviations from the average 
Table 3 The genes of B. cardium HPQL genome in COG functional categories

\begin{tabular}{|c|c|c|}
\hline $\begin{array}{l}\text { Functional_ } \\
\text { class }\end{array}$ & Class_description & Gene_number \\
\hline $\mathrm{C}$ & Energy production and conversion & 87 \\
\hline D & $\begin{array}{l}\text { Cell cycle control, cell division, } \\
\text { chromosome partitioning }\end{array}$ & 25 \\
\hline E & Amino acid transport and metabolism & 89 \\
\hline $\mathrm{F}$ & Nucleotide transport and metabolism & 52 \\
\hline G & Carbohydrate transport and metabolism & 46 \\
\hline $\mathrm{H}$ & Coenzyme transport and metabolism & 87 \\
\hline । & Lipid transport and metabolism & 56 \\
\hline J & $\begin{array}{l}\text { Translation, ribosomal structure and } \\
\text { biogenesis }\end{array}$ & 166 \\
\hline K & Transcription & 51 \\
\hline L & Replication, recombination and repair & 77 \\
\hline M & Cell wall/membrane/envelope biogenesis & 148 \\
\hline N & Cell motility & 12 \\
\hline $\mathrm{O}$ & $\begin{array}{l}\text { Posttranslational modification, protein } \\
\text { turnover, chaperones }\end{array}$ & 82 \\
\hline P & Inorganic ion transport and metabolism & 63 \\
\hline Q & $\begin{array}{l}\text { Secondary metabolites biosynthesis, } \\
\text { transport and catabolism }\end{array}$ & 19 \\
\hline R & General function prediction only & 98 \\
\hline S & Function unknown & 62 \\
\hline $\mathrm{T}$ & Signal transduction mechanisms & 37 \\
\hline U & $\begin{array}{l}\text { Intracellular trafficking, secretion, and } \\
\text { vesicular transport }\end{array}$ & 23 \\
\hline V & Defense mechanisms & 44 \\
\hline$x$ & Mobilome: prophages, transposons & 8 \\
\hline
\end{tabular}

(Additional file 2 Table S2) and four toxin-antitoxin (Additional file 8 Sheet S6) were predicted from the whole genome sequence of $B$. cardium HPQL. Moreover, comparative genomic analysis between the $B$. cardium HPQL, B. cardium (downloaded from NCBI PRJNA490389), B. zoohelcum ATCC 43767, B. zoohelcum CCUG 30536, B. zoohelcum NCTC 11660 and B. zoohelcum NCTC 11661 genome also demonstrated the evolutionary divergence of $B$. cardium HPQL from $B$. Zoohelcum spp. (Fig. 4). The relatively low sequence homology observed for the newly isolated B. cardium sp. with $B$. zoohelcum implied that the HPQL strain is a new member of the Bergeyella genus. Further comparative genomic analysis of the two $B$. cardium strains revealed 259 genes specific to B. cardium HPQL and 80 genes specific to another $B$. cardium strain.

\section{Original analysis of the $B$. cardium related to infective endocarditis}

To further elucidate the possible origin of the new B.cardium sp. strain, 16S rRNA sequences of the Bergeyella spp. were downloaded from NCBI for phylogenetic analysis. The analysis results demonstrated that strains homologous to B. zoohelcum clustered into one group, while strains homologous to the $B$. cardium strain clustered into another (Fig. 5). Interestingly, strains homologous to $B$. zoohelcum were isolated from animals, while the strains homologous to $B$. cardium were isolated from Homo sapiens. Moreover, two uncultured oral bacterial clones were identified with strong similarity to $B$. cardium sp., indicating that these strains also belong to the B. cardium sp.

\section{Discussion}

Little is known about the genus Bergeyella with B. zoohelcum being the only well described zoonotic pathogen currently afflicting humans [6, 7]. Recently, worldwide, 4 cases of B. cardium sp. have been reported as being isolated from patients with infective endocarditis $[3,5,12]$. The isolates were recognized as a novel strains belonging to the genus Bergeyella. In this study, we reported an additional new isolate belonging to the Bergeyella genus, from blood cultures of infective endocarditis patients. Results from NCBI BLASTN and phylogenetic analyses reveal that the new isolate belonged to $B$. cardium (Fig. 1). The 4 previously reported cases together with our new discovery clearly suggest that $B$. cardium sp. is correlative with human infective endocarditis. However, few studies have examined the fundamental biological properties of these new strains. Herein, we provide detailed biological characterization and whole genome sequencing of the newly isolated B. cardium sp. Our study may, therefore, serve to provide fundamental information to better understand this newly identified pathogen.

Consistent with other four reported cases, our isolate was also fastidious and was found to grow slowly on blood agar. The fastidious nature of the B. cardium sp. may account for their rare isolation. In addition, the newly identified strain exhibited irregular rod-shaped cells similar to B. cardium PU13217 [12]. Biochemical analysis using API card was also carried out, which may provide better understanding of this new strain of Bergeyella. Furthermore, our AST results were consistent with that observed for strain $13-7^{\mathrm{T}}$, demonstrating similar MIC susceptibilities in response to antimicrobial agents (Table 1). Currently there are no clearly defined standards described by NCCLS/CLSI for antibiotic susceptibility testing or breakpoints for B. cardium; however, our AST data, together with previous studies [3, 12], suggest effective targeted antibiotics for treatment of infections with this bacterial species.

We also sequenced the complete genome of B. cardium strain HPQL. To our knowledge, this is the first complete genome sequencing performed on any 


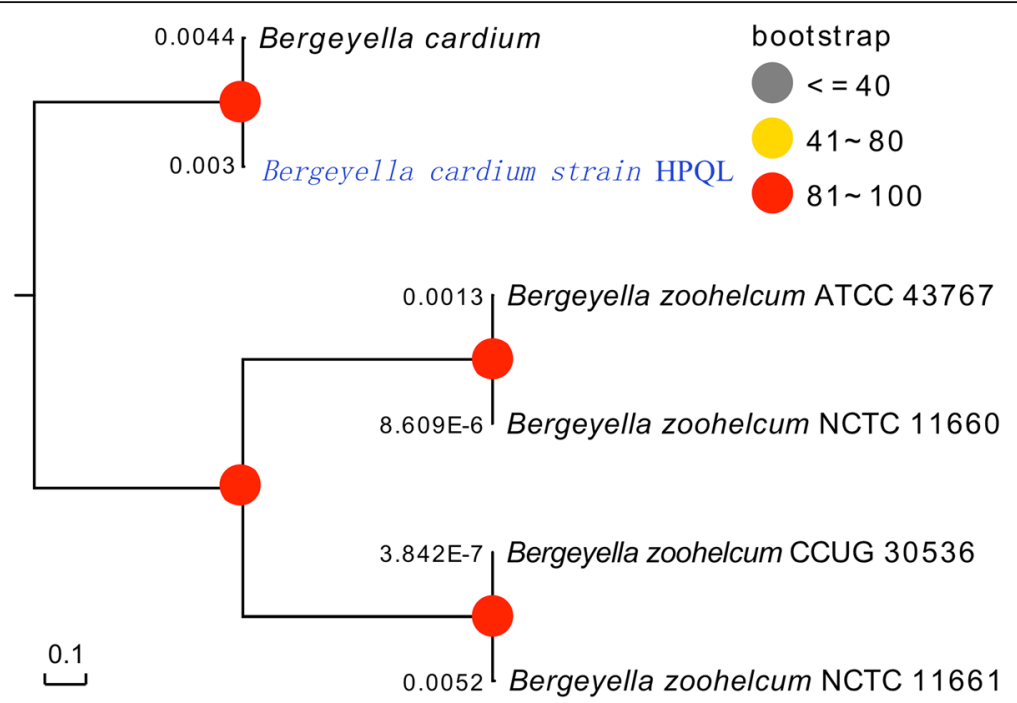

Fig. 4 Comparative genomic analysis. Comparative genomic analysis between the B. cardium HPQL, B. cardium (downloaded from NCBI PRJNA490389), B. zoohelcum ATCC 43767, B. zoohelcum CCUG 30536, B. zoohelcum NCTC 11660 and B. zoohelcum NCTC 11661 genomes was carried out. Phylogenetic tree based on core genome analysis

Bergeyella spp. Analysis results revealed 12 genes related to antibiotic resistance (Additional file 4 Sheet S2), including 3 that related to fluoroquinolone resistance, which is consistent with our in vitro AST analysis results. Sequencing results also revealed 162 genes associated with encoding virulence factors (Additional file 5 Sheet S3 and Additional file 6 Sheet S4). Identification of these genes serve to the current understanding of the mechanisms responsible for the pathogenic effects elicited by B. cardium strains.

The $B$. cardium strains isolated from this human patient were phylogenetically unique compared to the strains isolated from animals (Fig. 5), suggesting that the newly identified strains may originate from different sources than those that infect animals.

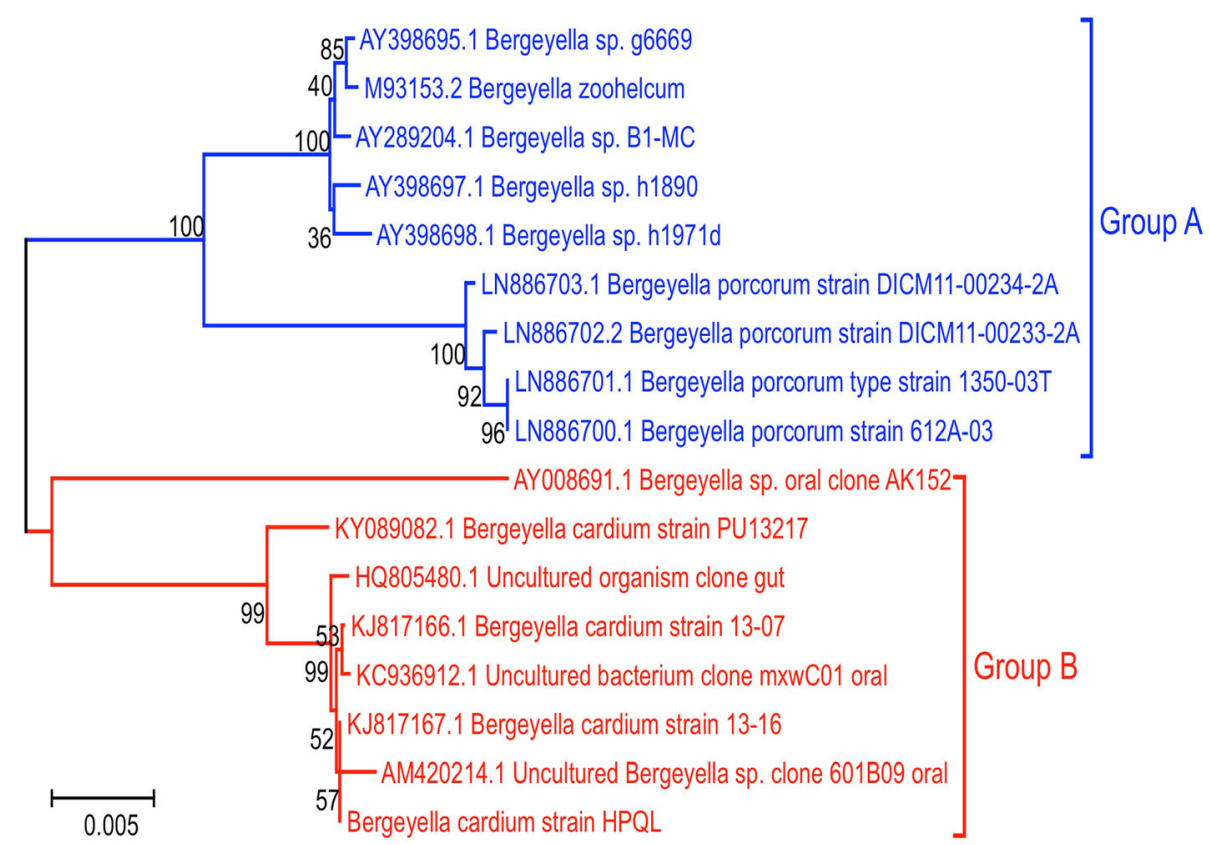

Fig. 5 Phylogenetic tree based on 165 ribosomal DNA sequences from multiple Bergeyella spp. Phylogenetic analysis of Bergeyella zoohelcum (Group A, animal original) and (Group B, human original) homologous to Bergeyella cardium strain. The phylogenetic tree was created using the Neighbor-Joining algorithm. The branches are scaled in terms of the expected number of substitutions per site 


\section{Conclusions}

Our data, collectively with other studies, clearly document that $B$. cardium strains are important, newly identified, human pathogens. The phylogenetic, phenotypic and morphological results together with the whole genome sequencing serve to extensively expand the current knowledge on the newly identified Bergeyella spp. as it relates to human infective endocarditis. Furthermore, our results provide insights into effective clinical diagnosis and treatment of this pathogen. We also suggest that this specific strain of $B$. cardium originated from the human oral cavity, though direct evidence of this was lacking. Future studies should focus on elucidating the pathogenic mechanisms elicited by this newly identified pathogen.

\section{Methods}

\section{Bacteria isolation}

A 63-year-old male presented to Qilu Hospital at Shandong University, Jinan, China, on April 26, 2016 with intermittent fever, fatigue, and chest distress for the previous 10 months. Ultrasonic cardiogram revealed infective endocarditis with valvular disease. Blood samples were sent to the microbiology laboratory for culturing on April 30, 2016. The blood cultures were incubated in the Bactec system (Becton Dickinson, Franklin Lakes, NJ) until a positive result was obtained. The positive blood cultures were inoculated onto Columbia blood agar, MacConkey agar, and Chocolate agar and incubated (Thermo Fisher Scientific, USA) at $35^{\circ} \mathrm{C}$ until visible colonies appeared. Colonies were purified using blood agar for further analysis.

\section{Phylogenetic analysis}

The nucleotide sequences of $16 \mathrm{~S}$ rRNA genes from different bacterial strains were downloaded from the NCBI database (http://www.ncbi.nlm.nih.gov) and aligned using the ClustalX computer program. The aligned sequences were refined and phylogenetically analyzed using distance/neighbor joining (NJ) and maximum-likelihood (ML) algorithms with the Poisson correction distance model in the MEGA software package [13] to infer their phylogenetic relationships. The bootstrapping supports for the interior branch length of the trees were from 1000 replicates.

\section{Morphological, physiological and biochemical characterization}

Morphological characterization of the isolated bacterial strain was carried out as previously described [14]. Growth was examined on Columbia blood, MacConkey and Chocolate agar. The strain was further biochemically characterized using API NH card (bioMérieux, Marcy l'Étoile, France) according to the manufacturer's instructions.

\section{Antibiotic sensitivity analysis}

Both the Vitek 2 system (bioMérieux, Marcy l'Étoile, France) and PDM Epsilometer test (E test) were employed to determine the antibiotic susceptibility of the isolated strain. For the Vitek 2 system, the cell density of the bacterial colony was adjusted to a density of $0.5 \mathrm{McFarland}$ with $0.45 \%$ saline; $145 \mu \mathrm{L}$ of the bacterial suspension was then added into $3 \mathrm{~mL}$ of $0.45 \%$ saline solution to further adjust the bacterial cell density. The suspension vials were then applied to the Vitek GN09 card and loaded into the Vitek 2 automated readerincubator for analysis. For the E test, the $0.5 \mathrm{McF}$ arland bacterial cell suspension were surface plated onto Blood agar plates, using a sterile swab to produce an even inoculum [15]. The plates were then incubated for $96 \mathrm{~h}$ (Thermo Fisher Scientific, USA) at $35^{\circ} \mathrm{C}$. The minimum inhibitory concentration (MIC) was determined to be the point where the elliptical zone of growth inhibition intersected with the MIC scale on the E test strip [15]. Sensitivities to penicillin, ceftriaxone, cefepime, cefotaxime, meropenem, imipenem, tigecycline, amoxicillin/clavulanate potassium, sulfamethoxazole, levofloxacin, ciprofloxacin, chloramphenicol, azithromycin, and gentamycin were examined.

\section{Genome sequencing and assembly}

Genomic sequencing and assembly were carried out at Novogen Bioinformatics Technology Co., Ltd. (Beijing, China). Single-molecule real-time (SMRT ${ }^{\circ}$ ) sequencing was performed using a Pacific Biosciences RSII sequencer (PacBio, Menlo Park, CA) according to the manufacturer's instructuions (MagBead Standard Seq v2 loading, $1 \times 180$ min movie) using P4-C2 chemistry. The low-quality reads were filtered by the SMRT 2.3.0 and the filtered reads were then assembled to generate one contig without gaps. Hierarchical Genome Assembly Process (HGAP) pipeline was used for the whole genome assemble.

\section{Genome annotations}

The assembled genome sequence was annotated further. Small RNAs (sRNAs) were predicted by BLAST against the Rfam [16] database. tRNAscan-SE [17] was then used to predicted transfer RNA (tRNA) genes, while the rRNAmmer server [18] was used to predict ribosomal RNA (rRNA) genes. RepeatMasker [19] and Tandem Repeat Finder [20] were applied to predict repetitive sequences and tandem repeats, respectively. A whole genome alignment (E-value less than 1e-5 and a minimal alignment length percentage $>40 \%$ ) against 6 databases, namely Clusters of Orthologous Groups (COG), Kyoto Encyclopedia of Genes and Genomes (KEGG), NCBI nonredundant (NR), Swiss-Prot, Gene Ontology (GO) and Translated EMBL (TrEMBL) was performed to predict gene functions [21-27]. ISFinder blast (https://www-is. 
biotoul.fr/blast.php) was used to predicted IS sequences while CRISPRdigger (https://omictools.com/crisprdigger -tool) [28] was used to predict CRISPR sequences. Prophage was predicted using PHASTER (http://phaster.ca) and IslandPath-DIOMB [29] was used to predict genome islands. RASTA-Bacteria (http://genoweb1.irisa.fr/duals/ RASTA-Bacteria/) was used to identify toxin-antitoxins. The methylation data had been submitted to REBASE database for restriction modification system analysis.

\section{Prediction of genes related to antibiotic resistance and virulence factors}

The genome sequences of the HPQL bacterial strain were submitted to the Virulence Factors of Pathogenic Bacteria (VFDB) [30], Comprehensive Antibiotic Research Database (CARD) [31] and Pathogen-Host Interactions database (PHI) [32] databases to predict which genes were related to antibiotic resistance and virulence factors.

\section{Comparative genomics analysis}

Comparative genomic analysis was performed between the $B$. cardium HPQL genome, $B$. cardium (downloaded from NCBI PRJNA490389) B. zoohelcum ATCC 43767 genome (downloaded from NCBI), the B. zoohelcum CCUG 30536 genome (downloaded from NCBI), B. zoohelcum NCTC 11660 genome (downloaded from NCBI), and B. zoohelcum NCTC 11661 (downloaded from NCBI). Core genes and specific genes were analyzed via CD-HIT rapid clustering of similar proteins software with the threshold set to $50 \%$ pairwise identity and a 0.7 cutoff in length difference of amino acids [25, 33, 34]. A phylogenetic tree was also constructed using the TreeBeST [35] according to the PhyML method, and the setting of bootstraps was 1,000 with the orthologous genes.

\section{Nucleotide sequence accession numbers}

The obtained genome sequence for B. cardium HPQL was deposited in GenBank under the accession numbers CP029149.

\section{Supplementary information}

Supplementary information accompanies this paper at https://doi.org/10. 1186/s12866-020-1715-0.

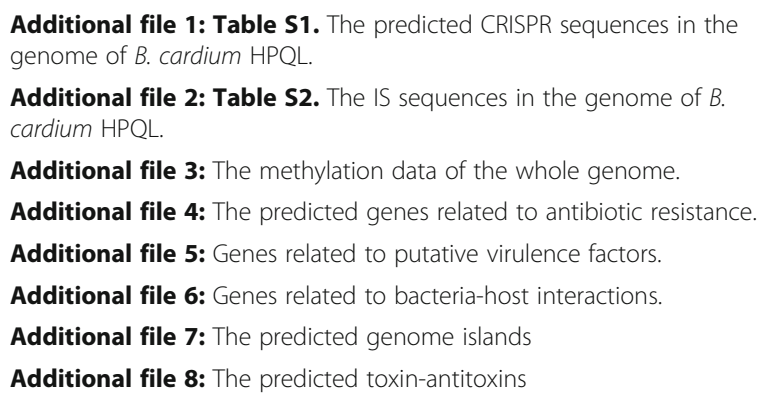

\section{Abbreviations}

B. cardium: Bergeyella cardium; CARD: Comprehensive Antibiotic Research Database; CDS: Coding sequences; COG: Clusters of Orthologous Group; ESR: Erythrocyte sedimentation rate; GO: Gene Ontology; HPQL: Hongwei Pan from QiLu hospital; KEGG: Kyoto Encyclopedia of Genes and Genomes; MIC: Minimum inhibitory concentration; ML: Maximum likelihood;

NJ: Neighbor joining; NR: NCBI non-redundant database; PHI: Pathogen-Host Interactions database; TrEMBL: Translated EMBL; VFDB: Virulence Factors of Pathogenic Bacteria

\section{Acknowledgements}

The authors thank Yong Li, Xiaoli Zhang, Yue Wu, Hongxia Zhou, Ying Wang for their help during carrying out the experiments. The authors thank Qiang Feng, Tianyong Sun and Lixiang Li for their help in data analysis. We would like to thank Editage for English language editing.

\section{Authors' contributions}

$Y Z$, ES and HP conceived and designed the experiments; HP and LW, performed the experiments; HP, YZ, and ES wrote the paper. All authors read and approved the final manuscript.

\section{Funding}

The work was financially supported by the National Natural Science Foundation of China (No. 81401709), Resident standardized training research of Qilu Hospital of Shandong University (Grant No. ZPZX2017A05), Qilu Hospital Clinical Practical New Technology Fund, the Key Research Foundation (No. 2015GSF118114 and No. 2016GSF201122) of Shandong Province, China, Natural Science Foundation (No. ZR2017MH044) of Shandong Province, China. The funders had no role in study design, data collection and interpretation, or the decision to submit the work for publication.

\section{Availability of data and materials}

The obtained genome sequence for B. cardium HPQL was deposited in GenBank under the accession numbers CP029149. In addition, the methylation data of the whole genome, whole genome sequences and predicted restriction modification system were also available in REBASE database (http://rebase.neb.com/rebase/private/pacbio_Pan15.html). All data generated or analysed during this study are included in this published article and its supplementary information files. The datasets used and/or analysed during the current study are also available from the corresponding author on reasonable request.

\section{Ethics approval and consent to participate}

This study was approved by the ethics committee of Qilu Hospital, Shandong University, Jinan, People's Republic of China (protocol KYLL-2019 (KS)-125). All subjects provided written informed consent before their inclusion in the study.

\section{Consent for publication}

Not applicable.

\section{Competing interests}

The authors declare that they have no competing interests.

Received: 22 August 2019 Accepted: 29 January 2020

Published online: 12 February 2020

\section{References}

1. Fukunaga M, Goya M, Nagashima M, Hiroshima K, Yamada T, An Y, Hayashi K, Makihara Y, Ohe M, Ichihashi K, et al. Identification of causative organism in cardiac implantable electronic device infections. J Cardiol. 2017;70(5):411-5.

2. Tempesta M, Campanella A, Maviglia S. Acinetobacter baumannii and cardiac impairment. Increasingly important nosocomial pathogen. Int J Cardiol. 2015;197:164-5.

3. Sohn KM, Huh K, Baek JY, Kim YS, Kang Cl, Peck KR, Lee NY, Song JH, Ko KS, Chung DR. A new causative bacteria of infective endocarditis, Bergeyella cardium sp. nov. Diagn Microbiol Infect Dis. 2015;81(3):213-6. 
4. Chen Y, Liao K, Ai L, Guo P, Huang H, Wu Z, Liu M. Bacteremia caused by Bergeyella zoohelcum in an infective endocarditis patient: case report and review of literature. BMC Infect Dis. 2017;17(1):271.

5. Mulliken JS, Langelier C, Budak JZ, Miller S, Dynerman D, Hao S, Li LM, Crawford E, Lyden A, Woodworth MH, et al. Bergeyella cardium: Clinical Characteristics and Draft Genome of an Emerging Pathogen in Native and Prosthetic Valve Endocarditis. Open Forum Infect Dis. 2019;6(4):ofz134.

6. Lin WR, Chen YS, Liu YC. Cellulitis and bacteremia caused by Bergeyella zoohelcum. J Formos Med Assoc. 2007;106(7):573-6.

7. Shukla SK, Paustian DL, Stockwell PJ, Morey RE, Jordan JG, Levett PN, Frank DN, Reed KD. Isolation of a fastidious Bergeyella species associated with cellulitis after a cat bite and a phylogenetic comparison with Bergeyella zoohelcum strains. J Clin Microbiol. 2004;42(1):290-3.

8. Bailie WE, Stowe EC, Schmitt AM. Aerobic bacterial flora of oral and nasal fluids of canines with reference to bacteria associated with bites. J Clin Microbiol. 1978;7(2):223-31

9. Kallman O, Lundberg C, Wretlind B, Ortqvist A. Gram-negative bacteria from patients seeking medical advice in Stockholm after the tsunami catastrophe. Scand J Infect Dis. 2006:38(6-7):448-50.

10. Beltran A, Bdiiwi S, Jani J, Recco RA, Go EE, Zaman MM. A case of Bergeyella zoohelcum bacteremia after ingestion of a dish prepared with goat blood. Clin Infect Dis. 2006;42(6):891-2.

11. Han YW, Ikegami A, Bissada NF, Herbst M, Redline RW, Ashmead GG. Transmission of an uncultivated Bergeyella strain from the oral cavity to amniotic fluid in a case of preterm birth. J Clin Microbiol. 2006;44(4):1475-83.

12. Guo LN, Li Y, Hsueh PR, Wang P, Zhao YP, Xu YC. Microbiological characteristics of a novel species most closely related to 'Bergeyella cardium' as a pathogen of infectious endocarditis. PLoS One. 2018; 13(1):e0191715.

13. Kumar S, Tamura K, Nei M. MEGA3: integrated software for molecular evolutionary genetics analysis and sequence alignment. Brief Bioinform. 2004;5(2):150-63.

14. Zamora L, Dominguez L, Fernandez-Garayzabal JF, Vela Al. Bergeyella porcorum sp. nov., isolated from pigs. Syst Appl Microbiol. 2016;39(3):160-3.

15. Joyce LF, Downes J, Stockman K, Andrew JH. Comparison of five methods, including the PDM Epsilometer test (E test), for antimicrobial susceptibility testing of Pseudomonas aeruginosa. J Clin Microbiol. 1992;30(10):2709-13.

16. Gardner PP, Daub J, Tate JG, Nawrocki EP, Kolbe DL, Lindgreen S, Wilkinson AC, Finn RD, Griffiths-Jones S, Eddy SR, et al. Rfam: updates to the RNA families database. Nucleic Acids Res. 2009;37(Database issue):D136-40.

17. Lowe TM, Eddy SR. tRNAscan-SE: a program for improved detection of transfer RNA genes in genomic sequence. Nucleic Acids Res. 1997; 25(5):955-64.

18. Lagesen $K$, Hallin P, Rodland EA, Staerfeldt HH, Rognes T, Ussery DW. RNAmmer: consistent and rapid annotation of ribosomal RNA genes. Nucleic Acids Res. 2007;35(9):3100-8.

19. Saha S, Bridges S, Magbanua ZV, Peterson DG. Empirical comparison of ab initio repeat finding programs. Nucleic Acids Res. 2008;36(7):2284-94.

20. Benson G. Tandem repeats finder: a program to analyze DNA sequences. Nucleic Acids Res. 1999;27(2):573-80.

21. Ashburner M, Ball CA, Blake JA, Botstein D, Butler H, Cherry JM, Davis AP, Dolinski K, Dwight SS, Eppig JT, et al. Gene ontology: tool for the unification of biology. The gene ontology consortium. Nat Genet. 2000;25(1):25-9.

22. Kanehisa M, Goto S, Kawashima S, Okuno Y, Hattori M. The KEGG resource for deciphering the genome. Nucleic Acids Res. 2004; 32(Database issue):D277-80.

23. Kanehisa M, Goto S, Hattori M, Aoki-Kinoshita KF, Itoh M, Kawashima S, Katayama T, Araki M, Hirakawa M. From genomics to chemical genomics: new developments in KEGG. Nucleic Acids Res. 2006; 34(Database issue):D354-7.

24. Tatusov RL, Fedorova ND, Jackson JD, Jacobs AR, Kiryutin B, Koonin EV, Krylov DM, Mazumder R, Mekhedov SL, Nikolskaya AN, et al. The COG database: an updated version includes eukaryotes. BMC Bioinformatics. 2003;4:41.

25. Li W, Jaroszewski L, Godzik A. Tolerating some redundancy significantly speeds up clustering of large protein databases. Bioinformatics. 2002; 18(1):77-82

26. Bairoch A, Apweiler R. The SWISS-PROT protein sequence database and its supplement TrEMBL in 2000. Nucleic Acids Res. 2000;28(1):45-8.

27. Magrane $M$, UniProt C. UniProt Knowledgebase: a hub of integrated protein data. Database. 2011;2011:bar009.
28. Grissa I, Vergnaud G, Pourcel C. CRISPRFinder: a web tool to identify clustered regularly interspaced short palindromic repeats. Nucleic Acids Res. 2007;35(Web Server issue):W52-7.

29. Hsiao W, Wan I, Jones SJ, Brinkman FS. IslandPath: aiding detection of genomic islands in prokaryotes. Bioinformatics. 2003;19(3):418-20.

30. Chen L, Xiong Z, Sun L, Yang J, Jin Q. VFDB 2012 update: toward the genetic diversity and molecular evolution of bacterial virulence factors. Nucleic Acids Res. 2012;40(Database issue):D641-5.

31. Jia B, Raphenya AR, Alcock B, Waglechner N, Guo P, Tsang KK, Lago BA, Dave BM, Pereira S, Sharma AN, et al. CARD 2017: expansion and modelcentric curation of the comprehensive antibiotic resistance database. Nucleic Acids Res. 2017;45(D1):D566-73.

32. Urban M, Pant $\mathrm{R}$, Raghunath A, Irvine AG, Pedro H, Hammond-Kosack KE. The pathogen-host interactions database (PHI-base): additions and future developments. Nucleic Acids Res. 2015;43(Database issue):D645-55.

33. Li W, Jaroszewski L, Godzik A. Clustering of highly homologous sequences to reduce the size of large protein databases. Bioinformatics. 2001;17(3):282-3

34. Li W, Godzik A. Cd-hit: a fast program for clustering and comparing large sets of protein or nucleotide sequences. Bioinformatics. 2006;22(13):1658-9.

35. Nandi T, Ong C, Singh AP, Boddey J, Atkins T, Sarkar-Tyson M, Essex-Lopresti $A E$, Chua HH, Pearson T, Kreisberg JF, et al. A genomic survey of positive selection in Burkholderia pseudomallei provides insights into the evolution of accidental virulence. PLoS Pathog. 2010;6(4):e1000845.

\section{Publisher's Note}

Springer Nature remains neutral with regard to jurisdictional claims in published maps and institutional affiliations.
Ready to submit your research? Choose BMC and benefit from:

- fast, convenient online submission

- thorough peer review by experienced researchers in your field

- rapid publication on acceptance

- support for research data, including large and complex data types

- gold Open Access which fosters wider collaboration and increased citations

- maximum visibility for your research: over $100 \mathrm{M}$ website views per year

At BMC, research is always in progress.

Learn more biomedcentral.com/submissions 